Australian

National

University

Crawford School of Public Policy

\title{
CAMA
}

Centre for Applied Macroeconomic Analysis

\section{Sectoral Employment Dynamics in Australia}

\section{CAMA Working Paper 51/2020 \\ May 2020}

Heather Anderson

Monash University

Centre for Applied Macroeconomic Analysis, ANU

\section{Giovanni Caggiano}

Monash University

Centre for Applied Macroeconomic Analysis, ANU

\section{Farshid Vahid}

Monash University

Centre for Applied Macroeconomic Analysis, ANU

\section{Benjamin Wong}

Monash University

Centre for Applied Macroeconomic Analysis, ANU 


\section{Abstract}

In the aftermath of the covid-19 pandemic, the prevention of further decline in aggregate employment and turning it around are high on the agenda of policymakers. To this end, it is imperative to have a disaggregated model of employment, given the unequal effects of covid-19 on employment in different sectors of the economy. In this paper we develop a multivariate time series model of employment in 19 sectors of the Australian economy. We provide the predictions of this model conditional on various scenarios that are based on the most recent quantitative information about sectoral employment in Australia. We estimate that the drop in total employment in the second quarter of 2020 will be in between 7 and 13 percentage points, compared to the second quarter of 2019. We also use this model to determine the long-run effect of a $1 \%$ increase in economic activity in any chosen sector on aggregate employment. Our findings point to manufacturing and construction sectors as those that might generate the largest positive spillovers for the rest of the economy. Moreover, we provide an interactive web-based app as well as an interactive spreadsheet that produce our model's 5-year forecasts based on any user-specified scenario for the current and following three quarters. As the covid-19 pandemic evolves and some restrictions are safely lifted or other restrictions become necessary, the sectoral employment multipliers together with the interactive tools produced here will provide useful information for policymakers.

\section{Keywords}

\section{JEL Classification}

\section{Address for correspondence:}

(E) cama.admin@anu.edu.au

\section{ISSN 2206-0332}

The Centre for Applied Macroeconomic Analysis in the Crawford School of Public Policy has been established to build strong links between professional macroeconomists. It provides a forum for quality macroeconomic research and discussion of policy issues between academia, government and the private sector.

The Crawford School of Public Policy is the Australian National University's public policy school, serving and influencing Australia, Asia and the Pacific through advanced policy research, graduate and executive education, and policy impact. 


\title{
Sectoral Employment Dynamics in Australia
}

\author{
Heather Anderson, Giovanni Caggiano, Farshid Vahid, and Benjamin Wong \\ Monash University and CAMA, ANU
}

May 14, 2020

\begin{abstract}
In the aftermath of the covid-19 pandemic, the prevention of further decline in aggregate employment and turning it around are high on the agenda of policymakers. To this end, it is imperative to have a disaggregated model of employment, given the unequal effects of covid-19 on employment in different sectors of the economy. In this paper we develop a multivariate time series model of employment in 19 sectors of the Australian economy. We provide the predictions of this model conditional on various scenarios that are based on the most recent quantitative information about sectoral employment in Australia. We estimate that the drop in total employment in the second quarter of 2020 will be in between 7 and 13 percentage points, compared to the second quarter of 2019. We also use this model to determine the long-run effect of a $1 \%$ increase in economic activity in any chosen sector on aggregate employment. Our findings point to manufacturing and construction sectors as those that might generate the largest positive spillovers for the rest of the economy. Moreover, we provide an interactive web-based app as well as an interactive spreadsheet that produce our model's 5-year forecasts based on any user-specified scenario for the current and following three quarters. As the covid-19 pandemic evolves and some restrictions are safely lifted or other restrictions become necessary, the sectoral employment multipliers together with the interactive tools produced here will provide useful information for policymakers.
\end{abstract}

\section{Introduction}

The introduction of policy measures designed to contain the covid-19 pandemic has had profound effects on economies around the world, and with the advent of social distancing policies, many countries have experienced sharp and substantial falls in employment. Many businesses have closed their doors for an indefinite period of time, while others are working with reduced hours or with skeleton staff structures. In Australia, the workforce numbered around thirteen million when the global pandemic was announced, and within two weeks, preliminary estimates made by the Australian Bureau of Statistics (ABS, 2020a) suggested job losses of 1.6 million.

Employment has long been used by economists as a coincident indicator of economic activity because of its sensitivity to changes in economic conditions (Burns and Mitchell, 1946; Stock and Watson, 1993). Further, employment is an important indicator of wellbeing, allowing workers to earn a living and prosper. Not surprisingly, economic 
policy makers in Australia and elsewhere have been implementing policies to avoid employee separation from their jobs, raising questions such as "What initial and long run effects will the covid-19 pandemic have on employment?" and then "What can be done to get employment (and output) back to its pre-covid 19 state?"

A focus on labour and employment is appropriate to monitor the state of the economy, since a pandemic does not destroy capital infrastructure. However, the defensive measures against the spread of the disease (such as travel bans and social distancing) have had serious effects on some sectors of the economy. The hospitality sector has suffered devastating job losses, and a large proportion of these workers are young and unskilled. The airlines have laid off thousands of workers, and those in performing arts have also been hard hit. On the other hand, the health industry has been stretched and overworked, while the education sector has adopted modern technology to deliver its services online. The construction industry has remained active and has been labelled the engine of the economy by the Australian Prime Minister.

This paper considers sectoral employment in Australia, and how employment in different sectors is likely to respond to and recover from covid-19. A key consideration is that although the pandemic affects employment in the entire economy, it affects different industries in different ways. We not only assess how the covid-19 shock will affect aggregate and specific industry demise and recovery in terms of jobs, but also assess how long this demise and recovery will take. Further, for each sector of the economy, we compute how stimulating activity in just that sector will affect total employment in the long-run. This analysis identifies those sectors that have largest spillover in terms of employment in other sectors, and will provide a useful guide for prioritizing the lifting of covid-19 related restrictions.

Our findings confirm that the sectors that will suffer the most from the covid-19 outbreak are "Accommodation \& Food Services" and "Arts \& Recreational Services", which in the worst case scenario might witness a 50 percent drop in employment in 2020Q2 compared to 2019Q2. Overall, total employment will experience a drop of between 7 and 13 percentage points relative to a year ago. We also find that the construction and manufacturing sectors are those that are capable of generating the largest spillovers for the rest of the economy, and as such they are key for recovery in employment growth.

Our analysis is based on the assumption that the structure of the economy that determined employment dynamics in Australia pre-covid-19 will not change as a result of covid-19. If this assumption is incorrect, the Lucas critique (Lucas, 1976) applies and invalidates our results. Since covid-19 has been an unprecedented event in recent history, we cannot offer any empirical evidence to justify our assumption. However, we believe that since the pandemic is not a result of any weakness in the structure of the Australian economic system, it is reasonable to believe that it will not break this structure, i.e. change the production functions of different sectors or the preferences of 
Australian consumers.

The analysis provided in the paper is up-to-date at the time of writing, but we also provide an online interactive tool, https://ebsmonash.shinyapps.io/Employment/, that allows the user to enter in the latest sectoral employment data as it becomes available and obtain updated predictions from our model for the future path of employment growth in the Australian economy. We provide the same product in an excel spreadsheet format as well, and this allows the user to obtain more details about our model's prediction of employment dynamics in each sector of the economy.

Our paper contributes to the recent economic literature that has tried to quantify the macroeconomic impact of the covid-19 outbreak. One strand of the literature has focused on the aggregate impact of the economic uncertainty induced by the covid-19 epidemic. Ludvigson et al. (2020) construct a costly disaster series for the US and estimate in a VAR setting that the coronavirus outbreak, modelled as a multiperiod shock, will reduce US real GDP by 12.75 percent by the end of 2020, and will cause a drop in employment in the service sector of 17 percent over the same time horizon. Baker et al. (2020) compute the rise in uncertainty that can be attributed to the epidemic and show that the induced uncertainty shock will generate a drop of about 11 percent of US GDP over a year. The impact of the coronavirus induced uncertainty on unemployment has been examined by Leduc and Liu (2020), who estimate an increase of 1 percent in the US unemployment rate due to the uncertainty channel of covid-19. While most studies have focused on the US economy, Caggiano et al. (2020) look at global real activity and estimate that the covid-19 outbreak will cause a drop in world output of 14 percent over a year. McKibbin and Fernando (2020) simulate a multi-country general equilibrium model and estimate that real GDP growth in both US and Australia will drop by 8 percent in one year. This study provides a complementary analysis to these contributions: while we do not aim at identifying the aggregate effects of the economic shock due to covid-19, we provide a forecast analysis of what will happen to employment, at a disaggregated level, as a consequence of the covid-19 economic shock in a small open economy like Australia.

A second strand of the literature has focused on the labor market impact of the covid19 shock. The International Labour Organization (2020) has provided initial estimates of the likely global impact on the labor force of covid-19. Their estimates point to a drop of a worldwide drop in hours worked in quarter 2 of 2020 of 6.7 percent. Based on their classification of sectors of activity according to the relative exposure to the covid19 shock, the ILO classifies "accommodation and food services", "real estate, business, and administrative activities", "manufacturing", and "wholesale and retail trade" as sectors at higher risk. The share of employment in at-risk sectors is estimated to be 37.5 percent worldwide, with Asia and the Pacific standing at 37.9 percent. Model-based analysis of the disaggregate impact of the covid-19 shock on labor market outcomes have been provided by Gregory et al. (2020) and Barrot et al. (2020). Gregory et al. (2020) 
look at the impact on employment, both aggregate and sectoral, of covid-19 through the lenses of a search-theoretic model, where workers are heterogeneous in productivity and ability to search for jobs. They calibrate their model using US data from the Longitudinal Employer and Household Dynamics, and then simulate it under different scenarios. The baseline simulation predicts that unemployment in the US would jump to 19 percent. The model attributes two thirds of the jump to temporary layoffs and one third to permanent layoffs. The recovery is L-shaped, with unemployment remaining at a permanently (after 4 years) higher than before the covid-19 outbreak. Gregory et al. (2020) provide simulations at the sectoral level, and show that unemployment will have the largest increases in "arts and entertainment" and "accommodation and food services" sectors. These sectors are also expected to witness permanent increases in unemployment, with rates 10 percentage points higher compared to the pre-shock level after 4 years. Barrot et al. (2020) use data for France and estimate that the combined effect of administrative closings, school and childcare closings, and strict confinement will lead to a drop of about 52 percent in the active workforce. They calculate the impact at the sectoral level and find that the sectors that are affected the most are "hotel restaurants" and "arts and leisure", followed by "agriculture" and "business services". They then use a production network model to provide an estimate of the total drop in GDP due to the restrictions imposed to contain the outbreak of the coronavirus. GDP is estimated to drop by 5.6 percentage points on an annual basis. Value added is estimated to drop in "downstream" sectors as "arts and leisure" and "hotel and restaurants" by 7.7 and 6.8 percent, respectively. Because of production linkages, "upstream" sectors like mining and "technical activities" are expected to suffer a drop in value added by even more: 8.8 and 7.6 percent respectively. Our analysis does not employ a theoretical model but uses real data on sectoral employment dynamics to simulate the dynamic impact of the coronavirus outbreak of sectoral and aggregate employment in Australia.

The rest of the paper develops as follows. Section 2 presents the data and the empirical methodology. Our main results are presented and discussed in Section 3, and Section 4 provides a brief conclusion.

\section{Data and Methodology}

We work with ABS Employment by Sector Data (ABS, 2020b), which records employed persons by the (ANZSIC) industry classification of their main occupation from 1984:Q4 to 2020:Q1 (see Figure 1). The least disaggregated level of ANZSIC divides the economy into 19 sectors. Table 1 provides some summary statistics relating to these sectors. The employment surveys on which the 2020:Q1 data are based were conducted in February 2020, so the 2020:Q1 observations are indicative of sectoral employment just before covid-19 started to affect the Australian economy. Close downs of business began on March 18th 2020, and full travel bans for non-citizens and permanent residents were 
imposed on March 19th. The raw data are illustrated in Figure 1. Seasonally adjusted

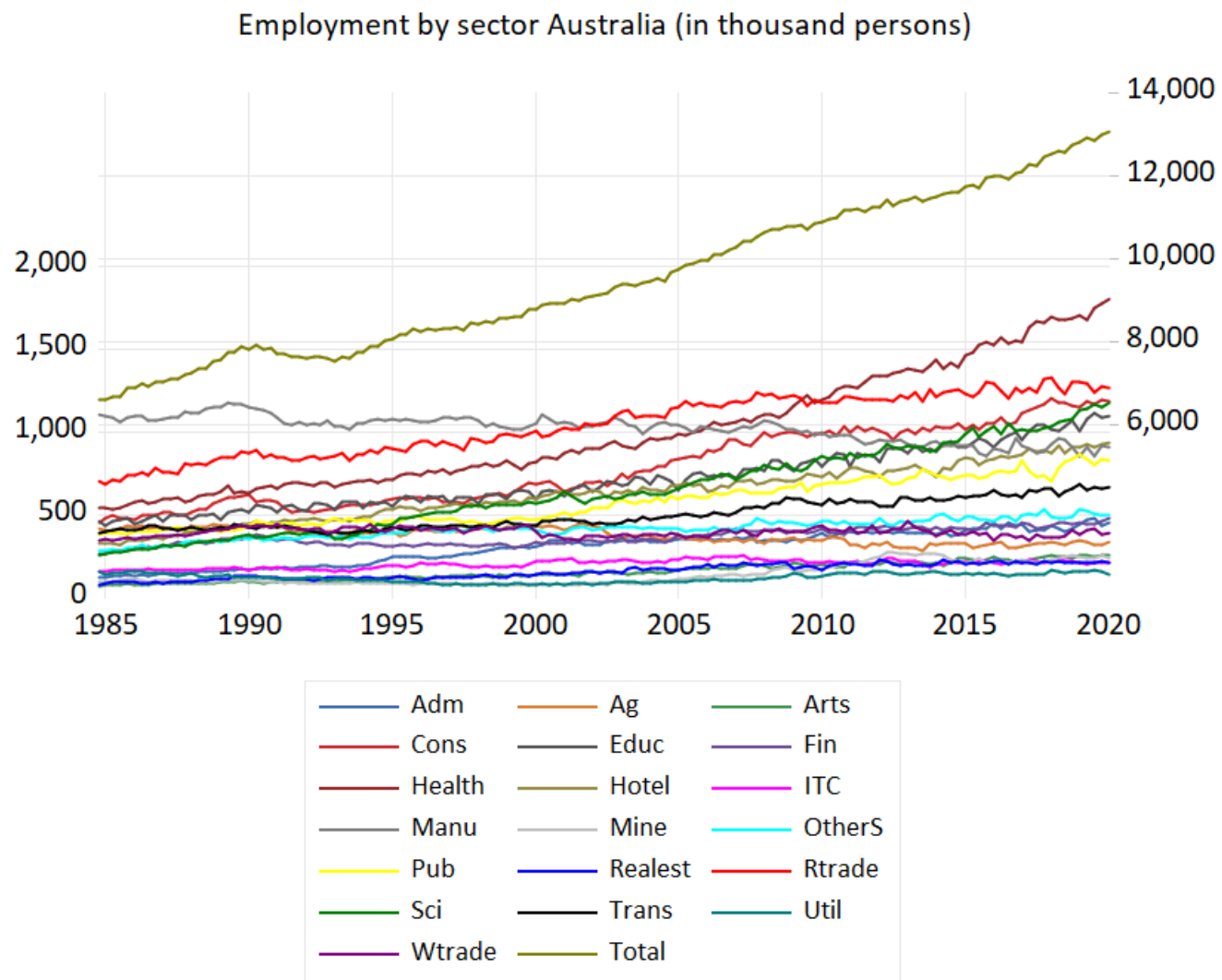

Figure 1: Employment in Australia (left axis: sectors, right axis: total)

data is available, but we work with the original data because seasonally adjusted sectoral employment figures do not add up to seasonally adjusted total employment. In addition, all newly unfolding information about changes in sectoral employment since covid-19 are in terms of raw figures. We apply seasonal differencing to the logarithm of original series to calculate year on year growth rates $^{1}$ and this transformation eliminates seasonal effects. We use the transformed data to develop a multivariate time series model for sectoral (and total) employment in Australia that can predict the evolution of employment in various scenarios during and after the pandemic.

Our multivariate dynamic model for sectoral employment growth rates allows lags of the growth rate of total employment to affect each sector as well as lags of the sectoral growth rates. The lags of total employment act as economy-wide factors that can affect each sector. We use a Bayesian VARX in which each sector is affected by lags of employment growth in all sectors and also lags of total employment growth ${ }^{2}$. The

\footnotetext{
${ }^{1}$ Specifically, if we denote employment at time $t$ by $y_{t}$, we use $g_{t}=100\left(\ln \left(y_{t}\right)-\ln \left(y_{t-4}\right)\right)$ to compute year on year employment growth at time $t$.

${ }^{2}$ We also consider a sparse VARX in which each equation includes only its own lags and the lags
} 
model can be written as:

$$
\mathbf{y}_{t}=\mathbf{c}+\mathbf{A}_{1} \mathbf{y}_{t-1}+\mathbf{A}_{2} \mathbf{y}_{t-2}+\mathbf{A}_{3} \mathbf{y}_{t-3}+\mathbf{A}_{4} \mathbf{y}_{t-4}+\boldsymbol{\Gamma} \mathbf{x}_{t-1}+\mathbf{u}_{t}
$$

where $\mathbf{y}_{t}$ is the $19 \times 1$ vector of sectoral employment growth rates at time $t$ and $\mathbf{x}_{t-1}$ is the $4 \times 1$ vector of 4 lags of the growth rate of total employment (the subscript $t-1$ indicates that this vector of variables is predetermined at time $t$ ), $\mathbf{c}$ is a vector of constants, $\mathbf{A}_{1}$ to $\mathbf{A}_{4}$ are $19 \times 19$ parameter matrices, $\boldsymbol{\Gamma}$ is a $19 \times 4$ parameter matrix, and $\mathbf{u}_{t}$ is a vector of reduced form errors. These errors are assumed to be normal with mean zero and variance-covariance matrix $\boldsymbol{\Sigma}$, and also independent over time. The BVARX model does not restrict $\mathbf{A}_{1}$ to $\mathbf{A}_{4}$ and $\boldsymbol{\Gamma}$, but shrinks their estimates towards zero.

The use of seasonally unadjusted data allows us to close the system with the identity that total employment is the sum of sectoral employment figures. As sectoral growth rates evolve, this system allows for sectoral shares to evolve endogenously. While this implies that the growth rate in total employment is a weighted average of sectoral employment growth rates with weights given by sectoral employment shares, perfect multicollinearity in the regressors of Equation (1) is avoided because sectoral employment shares change over time. More details about our model are provided in the Appendix.

\section{Results}

\subsection{Conditional forecasts}

We use our estimated model to provide "conditional forecasts" for sectoral and total employment (both in year on year growth rates and in actual employed numbers), given different scenarios. The methodology of conditional forecasting that we rely on is developed in Waggoner and Zha (1999).

There has not been a pandemic like covid-19, nor any other natural or man-made disasters of this scale in Australia during the sample period, so constructing reasonable scenarios for the covid-19 pandemic is challenging. Ludvigson et al. (2020) construct a disaster time series for the USA from the estimated costs of events such as Hurricane Katrina and the 9/11 terrorist attacks, and then use the response of indicators of economic activity to previous disasters to predict the effects of covid-19. One of their measures of economic activity is employment in the services sector. Australian disasters have been limited to periodic droughts and bushfires. The events such as $9 / 11$ or the global financial crisis do not stand out in the Australian context, even if we look at employment growth in sectors that are sensitive to world events such as transport or hospitality sectors. As Table 1 shows, the largest drops in employment in different

of growth rate of total employment. While the sparse model is more parsimonious, it makes a strong assumption that the spillover in employment from one sector to another is only through total employment. Since one of our goals is to measure the employment multiplier for each sector, we prefer the BVAR model that allows for a more general cross sectoral spillovers. 
sectors in Australia are likely to have been around the last recession in Australia, which was in 1991-1992.

We consider a no-covid scenario, and forecast year on year employment growth for every quarter from 2020Q2 to 2025Q1, in the absence of any unusual event. Coming out of a prolonged period of drought culminating in severe bushfires in late 2019 and early 2020, our model, by the force of its internal dynamics, predicts that employment growth would have smoothly increased to reach its historical mean throughout 2021, in the absence of the pandemic. The forecast of year on year growth rate in total employment in the absence of covid-19 is shown by the blue line in Figure 2 .

All covid scenarios that we consider are extrapolated from the information in ABS (2020c), Weekly Payroll Jobs and Wages in Australia, released on May 4, 2020. ABS derives this data from Single Touch Payroll (STP) data, which is provided to the Australian Taxation Office (ATO) by businesses with STP-enabled payroll or accounting software. It is important to note that this information does not include self-managed businesses and those who do not have STP-enabled payroll mechanisms. The latest released figures provide information on the change in employment in every sector in every week from March 14 to April 18. These data show the heterogeneous effect of covid19 on different sectors very clearly, with the Accommodation \& Food sector being the hardest hit followed by Arts \& Recreational Services. This pronounced heterogeneity makes it important to look at sectoral employment in this historically unprecedented episode, since crucial information would be lost if one looked at total employment only.

The first scenario, called scenario "O" (for optimistic), assumes that there will be no further changes in employment in any sector from April 18 until the end of the second quarter. This scenario is the most optimistic of the three covid scenarios that we consider. It assumes that the "job-keeper" program will successfully keep employees attached to their jobs in the rest of this quarter. We also assume that "job-keeper" remains in place during the following quarter, and then allow the model to determine how employment in each sector (and consequently total employment) will evolve. The assumptions of this scenario about the percentage change in employment in each sector in 2020Q2 relative to 2020Q1 are in the first of the three columns under "Scenario O" in Table 2. The second column under the same heading shows the implied year on year change in employment in different sectors. ${ }^{3}$ The third column under "Scenario O" shows the magnitude of shock (in standard deviations) needed to lead to the year on year (YoY) growth rate in the second column for each sector. A larger than four standard deviations shock has a very low probability of occurring under normal circumstances, and we can see that even in this optimistic scenario, there are several sectors that experience shocks with larger than four standard deviations in magnitude. Most notably, Accommodation \& Food Services has endured a 20 standard deviations negative shock. The next three

\footnotetext{
${ }^{3}$ We use $g_{t}^{*}=100 \times \frac{y_{t}-y_{t-4}}{y_{t-4}}$ to compute these year on year changes. Our model, however, models $g_{t}=100 \times \ln \left(\frac{y_{t}}{y_{t-4}}\right)=100 \times \ln \left(1+\frac{g_{t}^{*}}{100}\right)$, which is close to $g_{t}^{*}$ only when $g_{t}^{*}$ is a single digit number.
} 
hardest hit sectors are Arts \& Recreational Services, Other Services and Administrative \& Support Services. Interestingly, although the shock to total employment has historically been small relative to sectoral shocks, in this event it is very large (almost 15 standard deviations). This is because nearly all sectors have experienced coordinated negative shocks. The last row of the table shows the total number of jobs lost in each scenario. In "Scenario O", 985 thousand jobs are lost in 2020Q2 relative to 2020Q1. The forecasts of our model for total employment growth conditional on this scenario are plotted in green in Figure 2. In this scenario, YoY growth in total employment will remain negative until 2021Q4, and it will reach 2\% growth in 2022Q1.

The most pessimistic scenario that we consider, labelled "Scenario P", assumes that employment in each sector from April 18 to the end of the quarter will decline at the same rate that it did from March 14 to April 18. This means that if employment in a sector changed by $x$ percent between March 14 to April 18, the change in employment in that sector in 2020Q2 relative to 2020Q1 will be $100 \times\left(\left(1+\frac{x}{100}\right)^{2}-1\right)$. The first two columns under "Scenario P" provide these quarter on quarter changes and the implied year on year change in this scenario. The third column provides the reverse engineered reduced form shock that would lead to the assumed YoY growth rate. In this scenario, 11 of 19 sectors will have endured a larger than four standard deviation shocks to their employment, implying a 27 standard error shock in total employment and 1.8 million lost jobs by the end of 2020Q2. We assume that the employed numbers will then stay constant in the third quarter of 2020, and then it remains unrestricted after the end of that quarter. The forecasts of our model for total employment growth conditional on this scenario are shown by the red line in 2. In this scenario, the YoY growth rate in total employment will not turn positive until 2022Q1, and will reach $2 \%$ in 2022Q2.

Finally, we consider a middle-ground scenario, labelled "Scenario M", in which we assume that employment in each sector from April 18 will continue to change for another 6 weeks (until the end of May) at the weekly rate of change for that sector in the last two weeks prior to April $18^{4}$. The ABS data shows that in some sectors, employment change flattened in the last two weeks ending in April 18. We use the last two weeks rather than the last week to reduce the effect of measurement error in the weekly changes. The two columns under "Scenario M" provide these quarter on quarter changes and the implied year on year change in this scenario. In this scenario, 1.5 million jobs are lost by the end of 2020Q2. We assume that the employed numbers will then stay constant in the third quarter of 2020, and thereafter leave it unrestricted. The forecasts conditional on this scenario are shown by the yellow line in Figure 2. The implications of this scenario after one year are similar to those for Scenario P.

\footnotetext{
${ }^{4}$ Specifically, denote the change in employment for a sector from March 14 to April 18 by $x$ percent, the change in employment in this sector in the week from April 5 to April 11 by $x_{1}$ percent and the change from April 12 to April 18 by $x_{2}$ percent. Then the implicit weekly rate of change in the last two weeks is $\bar{x}=100 \times\left(\sqrt{\left(1+\frac{x_{1}}{100}\right)\left(1+\frac{x_{2}}{100}\right)}-1\right)$. Scenario M assumes that the change in employment in this sector in 2020Q2 relative 2020Q1 will be $100 \times\left[\left(1+\frac{x}{100}\right)\left(1+\frac{\bar{x}}{100}\right)^{6}-1\right]$.
} 


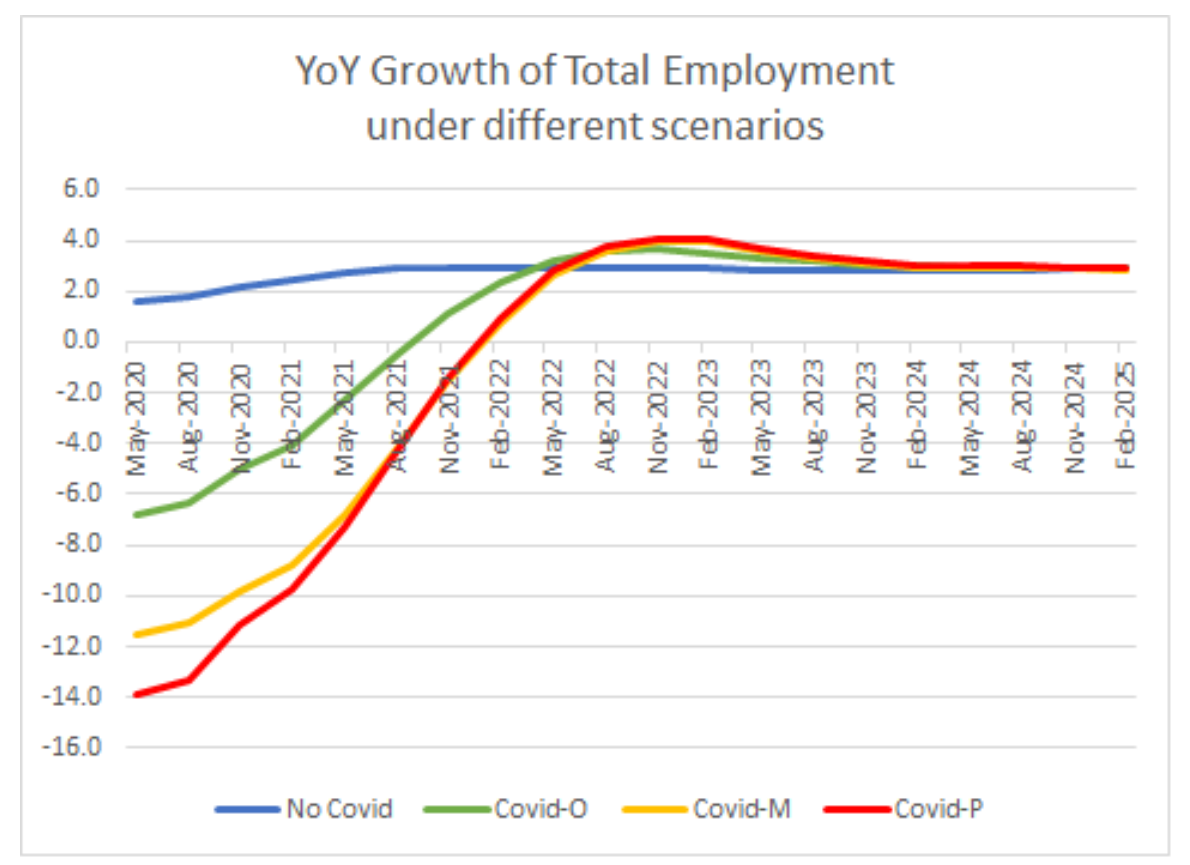

Figure 2: The conditional forecast of year on year growth rate for total employment under different scenarios

The three scenarios that we have considered here are illustrative of a much broader set of scenarios that might be of interest, so we have made an interactive web application at https://ebsmonash.shinyapps.io/Employment/ to facilitate the exploration of other scenarios. This application allows a user to enter more up-to-date data as it becomes available, or change the assumptions that we have made for the rest of 2020 and obtain the model's forecasts of employment growth over the next 5 years conditional on the user-specified input. A spreadsheet version of the same application is also available for download at https://github.com/farshid-vahid/Employment, and the user can enter different scenarios to obtain the prediction of our model for employment growth rates, as for the online application. Further, the spreadsheet version provides predictions for every sector, as well as the total.

\subsection{Sectoral employment multipliers}

When there is a one percent increase in employment in sector $j$ with all else held constant, total employment will simultaneously increase by sector $j$ 's share in total employment. In subsequent periods, this increase in employment in sector $j$ may have spillover effects onto other sectors, especially those that have close economic ties with sector $j$. Other sectors will also experience indirect effects given the increase in total employment. The long-run employment multiplier of sector $j$ is the effect of the initial increase in sector $j$ on total employment in the long-run. If this long-run effect is larger than the immediate effect, then stimulating economic activity in sector $j$ will have a positive spillover effect on total employment. 
We use our model to simulate the long-run multiplier for each sector, and report these in Table 3 for horizons of one year, two years and five years. Comparing these latter multipliers with those in the $\%$ share column in Table 1 , we find that the manufacturing and construction industries, followed by wholesale and retail trade generate strong positive spillover employment for the total economy. Policies that stimulate employment in these sectors will be especially effective in increasing total employment. Two observations are important to note here. Firstly, the positive spillovers are not simply related to the size of these sectors. As can be seen from Table 1, wholesale trade is not a big sector in terms of employment, while the health and education sectors are among the larger sectors of the economy. However, Table 3 show that wholesale trade generates strong and positive employment spillovers, while the health sector and education sectors do not generate positive spillovers in the long run. Secondly, as can be seen in Table 1, the age and education characteristics of the employees of the accommodation and food services sector, which is the sector that has been most affected by covid-19 and is unlikely to recover any time soon, are somewhat similar to the characteristics of the employees of the sectors with highest positive spillovers.

A curious finding is that the education sector has a large negative long-run employment multiplier. We think that this may be due to the fact that during the sample period there has been an increase in demand for education and training whenever other sectors are in a slump.

\section{Conclusion}

To the question of whether a stable dynamic economic system would not break if it were subjected to a 15 to 25 standard deviation shock, we respond that it probably would. We would then add that since such a shock is unprecedented in recent history, any answer to the question of what would happen after this system was subjected to such a huge shock, would have to be an opinion that could neither be supported nor refuted by the existing evidence. We add the predictions of our model, that is estimated using time series data prior to this shock, to the pool of opinions offered by experts. If some cross-correlations between employment in different sectors of the economy remain constant after the shock, we believe that this model can provide useful information. We do not claim that this is better than other opinions in the pool of expert opinions, but we believe that it is a useful addition to this pool.

We base our analysis on a sectoral employment model since the covid-19 shock has had vastly different effects on different sectors of the economy. We provide the predictions of the model conditional on various scenarios that are all based on the most recent quantitative information about sectoral employment in Australia. We provide an interactive web-page and a spreadsheet that allow a user to specify any scenario and see what our model predicts for the future growth rate of total employment conditional on 
that scenario.

The predictions of the model conditional on different scenarios is based on an assumption that there is no other discretionary intervention in the system. Of course an important question is how to intervene to stimulate the economy and counteract the economic effects of the pandemic. When thinking about policies to stimulate the economy and also recognising public health restrictions that constrain some sectors more than others, it is useful to think about sectors that could safely work and act as the engines of the economy. In this paper we estimate sectoral employment multipliers to identify such sectors. Our analysis, perhaps not surprisingly, identifies manufacturing and construction to be the sectors with highest positive spillovers in employment. 


\section{Appendix A BVAR Estimation}

We write our VARX model in the following way:

$$
\begin{aligned}
\mathbf{y}_{t} & =\mathbf{c}+\mathbf{A}_{1} \mathbf{y}_{t-1}+\ldots+\mathbf{A}_{4} \mathbf{y}_{t-4}+\boldsymbol{\Gamma}_{1} x_{t-1}+\ldots+\boldsymbol{\Gamma}_{4} x_{t-4}+\mathbf{u}_{t} \\
& =\left[\begin{array}{c}
c_{1} \\
\vdots \\
c_{n}
\end{array}\right]+\left[\begin{array}{cccccccccc}
a_{1}^{11} & \ldots & a_{1}^{1 n} & \ldots & a_{4}^{11} & \ldots & a_{4}^{1 n} & \gamma_{1}^{1} & \ldots & \gamma_{4}^{1} \\
\vdots & \ddots & \vdots & \vdots & \vdots & \ddots & \vdots & \vdots & \ddots & \vdots \\
a_{1}^{n 1} & \ldots & a_{1}^{n n} & \ldots & a_{4}^{n 1} & \ldots & a_{4}^{n n} & \gamma_{1}^{n} & \ldots & \gamma_{4}^{n}
\end{array}\right]\left[\begin{array}{c}
\mathbf{y}_{\mathbf{t}-1} \\
\vdots \\
\mathbf{y}_{\mathbf{t}-4} \\
x_{t-1} \\
\vdots \\
x_{t-4}
\end{array}\right]+\left[\begin{array}{c}
u_{1, t} \\
\vdots \\
u_{n, t}
\end{array}\right]
\end{aligned}
$$

where $\mathbb{E}\left(\mathbf{u}_{\mathbf{t}} \mathbf{u}_{\mathbf{t}}^{\prime}\right)=\boldsymbol{\Sigma}$ and $\mathbb{E}\left(\mathbf{u}_{\mathbf{t}} \mathbf{u}_{\mathbf{t}-\mathbf{i}}^{\prime}\right)=\mathbf{0}, \forall i>0$. The number of sectors is represented by $n=19$, and $\boldsymbol{c}$ represents the vector of constants. We include four lags of total employment growth $\left(x_{t-1}, \ldots x_{t-4}\right)$ in each equation as predetermined variables at time $t$. We note that these $x_{t-1}, \ldots x_{t-4}$ are not strictly exogenous since total employment is equal to the sum of employment in the 19 sectors.

We estimate the VARX using Bayesian methods by specifying a natural-conjugate Normal-Wishart prior which draws on elements of the Minnesota prior (e.g., see Litterman, 1986; Robertson and Tallman, 1999, for descriptions of the Minneosta prior), noting that our approach is fairly standard and has been utilized elsewhere in published work (e.g., Banbura et al., 2010). We apply shrinkage to the VAR slope coefficients using a Minnesota-type prior specification for the prior means and prior variances as follows:

$$
\begin{aligned}
\mathbb{E}\left[a_{i}^{j k}\right] & =\mathbb{E}\left[\gamma_{i}^{j}\right]=0 \\
\operatorname{Var}\left[a_{i}^{j k}\right] & = \begin{cases}\frac{\lambda^{2}}{i^{2}}, & j=k \\
\frac{\lambda^{2}}{i^{2}} \frac{\sigma_{j}^{2}}{\sigma_{k}^{2}}, & \text { otherwise }\end{cases} \\
\operatorname{Var}\left[\gamma_{i}^{j}\right] & =\frac{\lambda^{2}}{i^{2}} \frac{\sigma_{j}^{2}}{\sigma_{e}^{2}},
\end{aligned}
$$

where the degree of shrinkage is governed by the hyperparameter $\lambda$, with $\lambda \rightarrow 0$ shrinking to the assumption that year on year sectoral growth rates in the VAR are independent white noise processes.

We obtain $\sigma_{l}^{2}$ by taking the residual variances after fitting an $\operatorname{AR}(4)$ on the $l^{\text {th }}$ variable using least squares, which is common practice (e.g., Banbura et al., 2010; Koop, 2013). The term $1 / i^{2}$ governs the basic structure of the Minnesota Prior to down-weight more distant lags and the factor $\sigma_{j}^{2} / \sigma_{k}^{2}$ adjusts for the different scale of the data. We 
choose $\lambda=0.2$, which has been shown to be an appropriate choice (see, Carriero et al., 2015). $\sigma_{e}^{2}$ is the variance after fitting an $\mathrm{AR}(4)$ on total employment growth.

The natural conjugate Normal-Inverse-Wishart prior implies posterior moments that can be calculated either analytically or through the use of dummy observations. We will use dummy observations to estimate the BVAR (e.g., Banbura et al., 2010; Del Negro and Schorfheide, 2011; Woźniak, 2016).

In order to estimate the BVAR using dummy observations, we cast the VARX in Equation (2) into a system of multivariate regressions of the form

$$
Y=X \boldsymbol{\beta}+u,
$$

where $Y=\left[\mathbf{y}_{1}, \ldots, \mathbf{y}_{T}\right]^{\prime}, X=\left[X_{1}, \ldots, X_{T}\right]^{\prime}$ with $X_{t}=\left[\mathbf{y}_{t-1}^{\prime}, \ldots, \mathbf{y}_{t-4}^{\prime}, x_{t-1}, \ldots, x_{t-4}, 1\right]^{\prime}$ and $u=\left[u_{1}, \ldots, u_{T}\right]^{\prime}$. The Normal-Wishart prior distribution then takes the form

$$
\operatorname{vec}(\boldsymbol{\beta}) \mid \Sigma \sim \mathcal{N}\left(\operatorname{vec}\left(\boldsymbol{\beta}_{0}\right), \Sigma \otimes \Omega_{0}\right) \quad \text { and } \quad \Sigma \sim \mathcal{I} \mathcal{W}\left(S_{0}, a_{0}\right)
$$

where we set the prior parameters $\beta_{0}, \Omega_{0}, S_{0}$, and $a_{0}$ such that they are consistent with the structure given by Equations (3) to (5) and the expectation of $\Sigma$ being $\operatorname{diag}\left(\sigma_{1}^{2}, \ldots, \sigma_{n}^{2}\right)$. We follow (see e.g. Del Negro and Schorfheide, 2011; Woźniak, 2016) and implement our prior by defining dummy observations

$$
Y_{d}=\left(\begin{array}{c}
0_{n p+p, n} \\
\operatorname{diag}\left(\sigma_{1} \ldots \sigma_{n}\right) \\
0_{1 \times n}
\end{array}\right), \quad X_{d}=\left(\begin{array}{cc}
J_{p} \otimes \operatorname{diag}\left(\sigma_{1} \ldots \sigma_{n}, \sigma_{e}\right) / \lambda & 0_{(n p+p) \times 1} \\
0_{n, n p+p} & 0_{n \times 1} \\
0_{1, n p+p} & \epsilon
\end{array}\right)
$$

where $Y_{d}$ and $X_{d}$ are the dummy observations chosen according to Eqs. (4) and (5), $J_{p}=$ $\operatorname{diag}(1, \ldots, p), S_{0}=\left(Y_{d}-X_{d} B_{0}\right)^{\prime}\left(Y_{d}-X_{d} B_{0}\right), B_{0}=\left(X_{d}^{\prime} X_{d}\right)^{-1} X_{d} Y_{d}, \Omega_{0}=\left(X_{d}^{\prime} X_{d}\right)^{-1}$, and $a_{0}=T_{d}-n p-p-1$, where $T_{d}$ is the number of rows for both $Y_{d}$ and $X_{d} . \epsilon$ is a very small number to impose an uninformative and diffused prior on the constants. The first block of the dummy observations imposes the prior belief on the VAR slope coefficients and the second block contains the prior for the covariance matrix and the third block imposes the prior belief on the constants.

Consider the regression in Eq. (6) augmented with the dummy observations:

$$
Y^{*}=X^{*} \boldsymbol{\beta}+u^{*}
$$

where $Y^{*}=\left[Y^{\prime}, Y_{d}^{\prime}\right]^{\prime}, X^{*}=\left[X^{\prime}, X_{d}^{\prime}\right]^{\prime}$ and $u^{*}=\left[u^{\prime}, u_{d}^{\prime}\right]^{\prime}$. Estimating the BVAR then simply amounts to conducting least squares regression of $Y^{*}$ on $X^{*}$. The posterior 
distribution then has the form

$$
\begin{aligned}
\operatorname{vec}(\boldsymbol{\beta}) \mid \Sigma, Y & \sim \mathcal{N}\left(\operatorname{vec}(\tilde{\boldsymbol{\beta}}), \Sigma \otimes\left(X^{* \prime} X^{*}\right)^{-1}\right) \\
\Sigma \mid Y & \sim \mathcal{I} \mathcal{W}\left(\tilde{\Sigma}, T_{d}+T-n p+2\right),
\end{aligned}
$$

where $\tilde{\boldsymbol{\beta}}=\left(X^{* \prime} X^{*}\right)^{-1} X^{* \prime} Y^{*}$ and $\tilde{\Sigma}=\left(Y^{*}-X^{*} \tilde{\boldsymbol{\beta}}\right)^{\prime}\left(Y^{*}-X^{*} \tilde{\boldsymbol{\beta}}\right)$.

\section{References}

ABS (2020a). Household Impacts of Covid-19 Survey, 1 - 6 April, Australian Bureau of Statistics, cat. no. 4940.0, 2020.

ABS (2020b). Labour Force, Australia, Detailed, Quarterly Table 04, 'Employed persons by industry division of main job (ANZSIC)', time series spreadsheets, Australian Bureau of Statistics, cat. no. 6291.0.55.003, downloaded 18 April 2020.

ABS (2020c). Weekly Payroll Jobs and Wages in Australia, week ending 18 April 2020, Australian Bureau of Statistics cat. no. 6160.0.55.001, viewed 6 May 2020.

Baker, S., N. Bloom, S. Davis, and S. Terry (2020). Covid-Induced Economic Uncertainty. NBER Working Paper Working Paper No. 26983.

Banbura, M., D. Giannone, and L. Reichlin (2010). Large Bayesian Vector Auto Regressions. Journal of Applied Econometrics 25(1), 71-92.

Barrot, J. N., B. Grassi, and J. Sauvagnat (2020). Sectoral Effects of Social Distancing. Covid Economics. Vetted and Real-Time Papers 3, 85-102.

Burns, A. F. and W. C. Mitchell (1946). Measuring Business Cycles. New York: National Burreau of Economic Research.

Caggiano, G., E. Castelnuovo, and R. Kima (2020). The Global Effects of Covid-19Induced Uncertainty. CESifo Working Papers No. 8280.

Carriero, A., T. E. Clark, and M. Marcellino (2015, 01). Bayesian VARs: Specification Choices and Forecast Accuracy. Journal of Applied Econometrics 30(1), 46-73.

Del Negro, M. and F. Schorfheide (2011). Bayesian Macroeconometrics. In J. Geweke, G. Koop, and H. Van Dijk (Eds.), The Oxford Handbook of Bayesian Econometrics, pp. 293-389. Oxford University Press.

Gregory, V., G. Menzio, and D. Wiczer (2020). Pandemic Recession: L-Shaped or V-Shaped? Covid Economics. Vetted and Real-Time Papers 15, 88-109.

International Labour Organization (2020). ILO Monitor: Covid-19 and the World of Work.

Koop, G. M. (2013, 03). Forecasting with Medium and Large Bayesian VARs. Journal of Applied Econometrics 28(2), 177-203.

Leduc, S. and Z. Liu (2020). The Uncertainty Channel of the Coronavirus. FRBSF Economic Letter. 
Litterman, R. B. (1986, January). Forecasting with Bayesian Vector Autoregressions: Five Years of Experience. Journal of Business \& Economic Statistics 4 (1), 25-38.

Lucas, R. E. (1976). Econometric policy evaluation: A critique. Carnegie-Rochester Conference Series on Public Policy 1, 19-46.

Ludvigson, S., S. Ma, and S. Ng (2020). Covid-19 and the macroeconomic effects of costly disasters. Covid Economics. Vetted and Real-Time Papers 9 , 1-21.

McKibbin, W. and R. Fernando (2020). The Global Macroeconomic Impact of Covid-19: Seven Scenarios. Covid Economics. Vetted and Real-Time Papers 10, 116-156.

Robertson, J. C. and E. W. Tallman (1999). Vector Autoregressions: Forecasting and Reality. Economic Review 84(Q1), 4-18.

Stock, J. H. and M. W. Watson (Eds.) (1993). Business Cycles, Indicators and Forecasting. NBER Studies in Business Cycles. University of Chicago Press.

The Department of Education, Skills and Employment (2019). Australian Jobs 2019.

Waggoner, D. F. and T. Zha (1999). Conditional forecasts in dynamic multivariate models. Review of Economics and Statistics 81(4), 639-651.

Woźniak, T. (2016, 09). Bayesian Vector Autoregressions. Australian Economic Review 49(3), 365-380. 


\begin{tabular}{|c|c|c|}
\hline 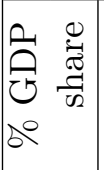 & 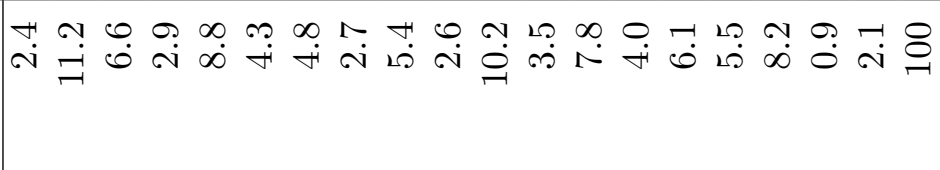 & \\
\hline 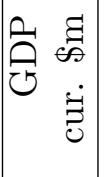 & 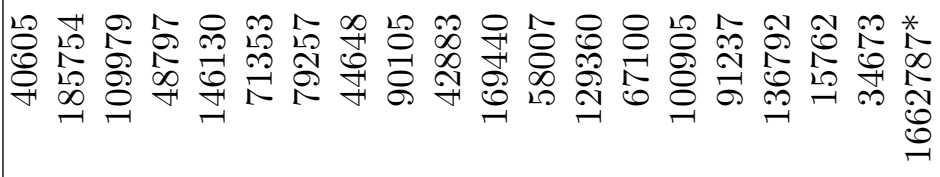 & \\
\hline 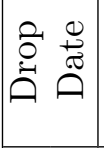 & 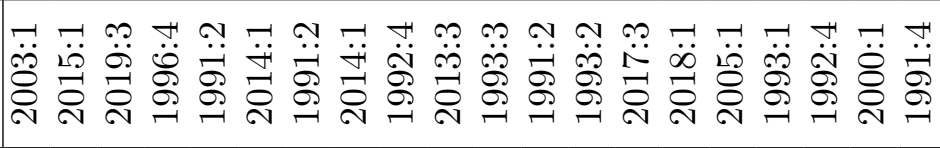 & \\
\hline 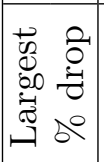 & 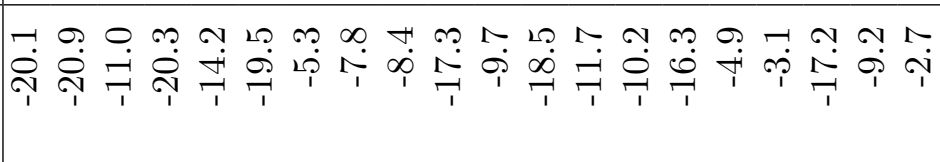 & \\
\hline 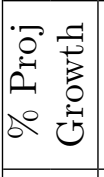 & 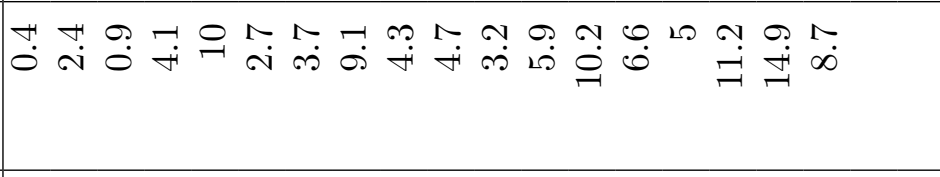 & \\
\hline 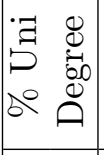 & 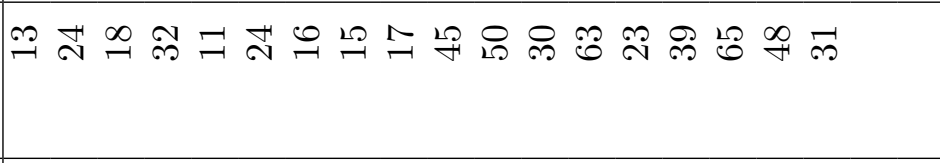 & \\
\hline 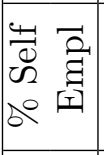 & 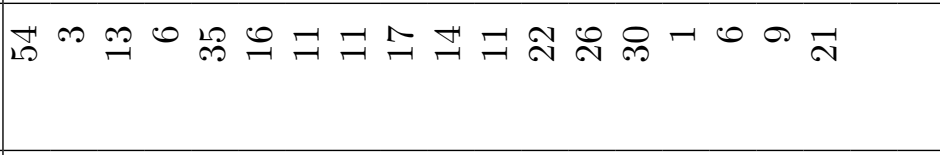 & \\
\hline 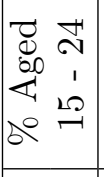 & 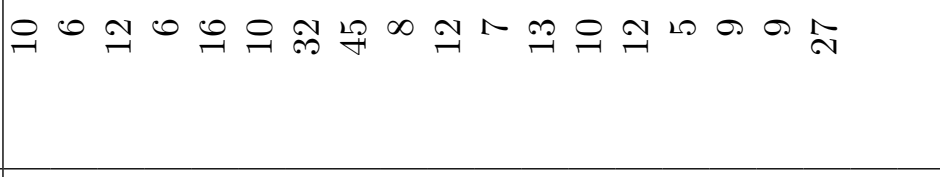 & \\
\hline 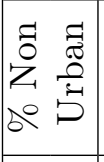 & 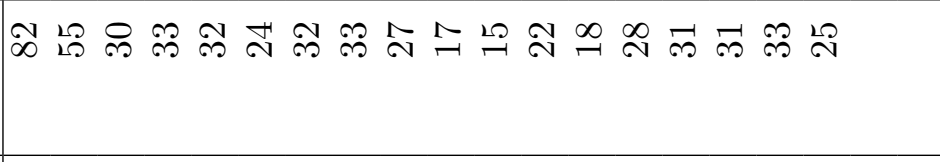 & \\
\hline 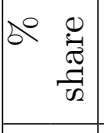 & 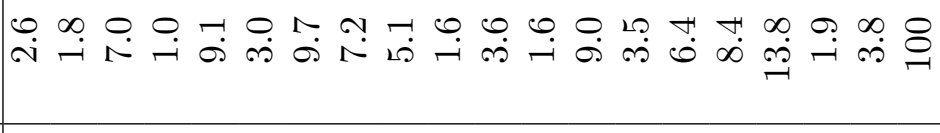 & \\
\hline 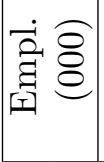 & 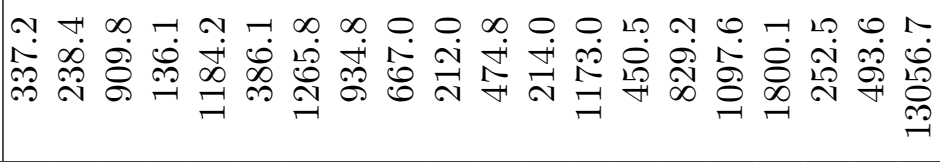 & \\
\hline 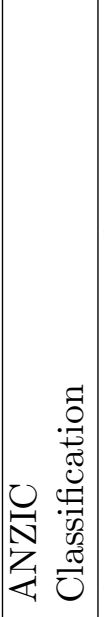 & 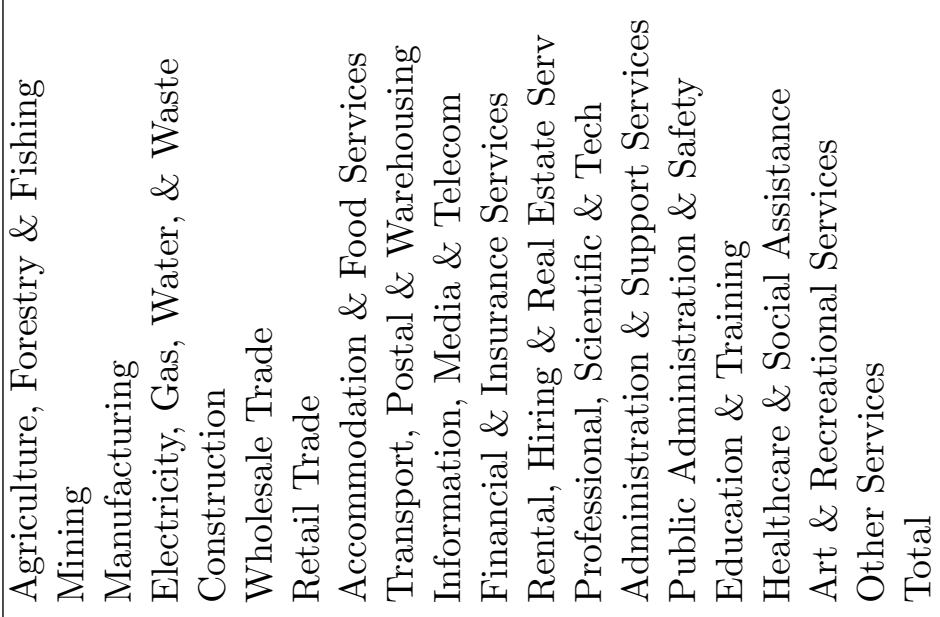 & \\
\hline
\end{tabular}




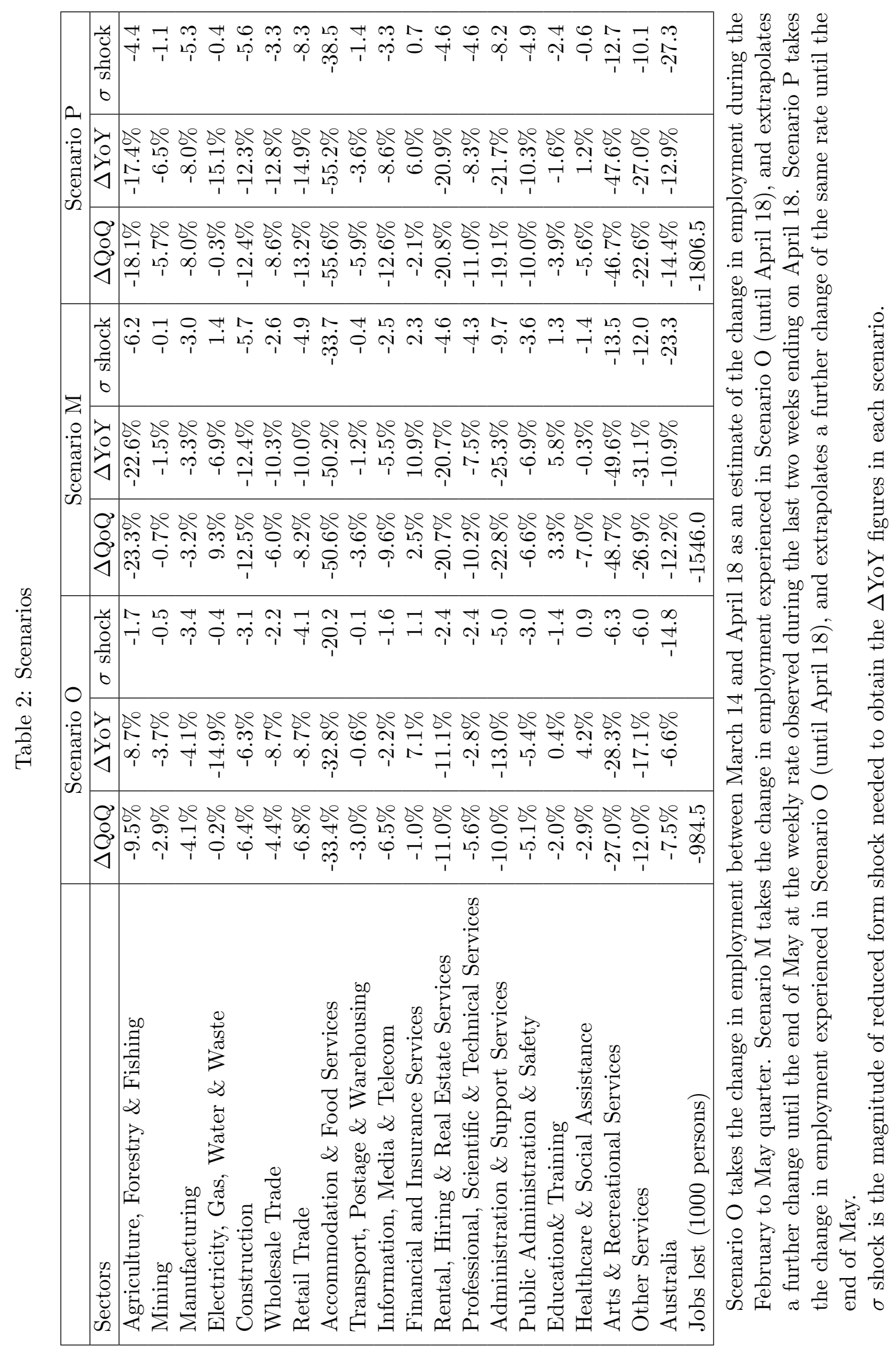




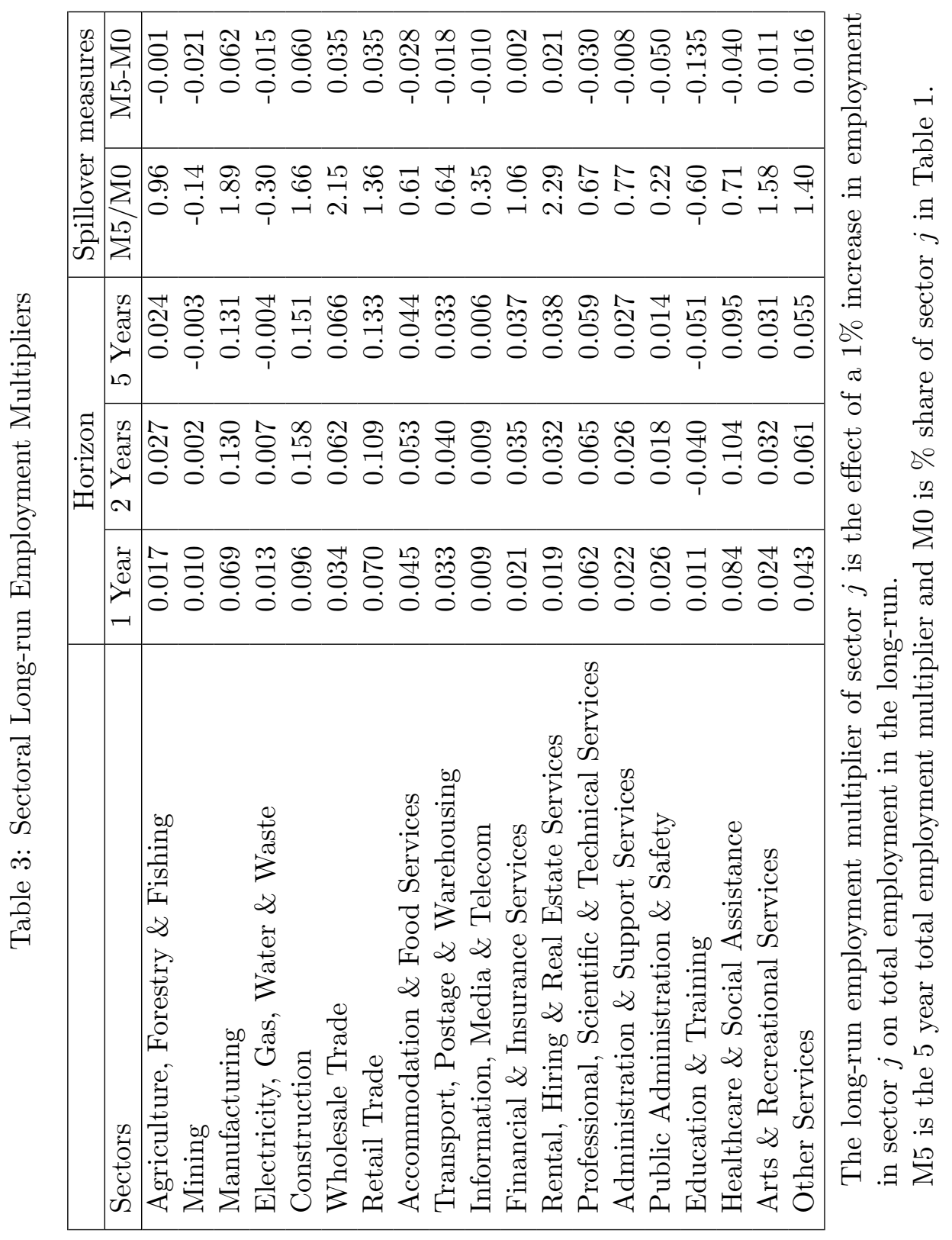

